\title{
Entre 0 algoritmo e a curadoria: programação radiofônica, gêneros musicais e repetição ${ }^{1}$
}

\section{Between algorithm and curation - Radio programming, music genres and repetition}

\author{
Marcelo Kischinhevsky ${ }^{2}$ \\ Gustavo Ferreira ${ }^{3}$ \\ Claudia Góest \\ Artur Seidel ${ }^{5}$ \\ Liana Monteiro 6
}

Resumo: Este artigo investiga o processo de construção da programação musical radiofônica, cada vez mais tensionada entre dois polos: a curadoria humana e a mediação algorítmica dos softwares de automação. No percurso, propõe-se uma reflexão sobre os papéis exercidos por categorias como gêneros musicais, diversidade e repetição. Parte-se da premissa de que a música permanece central para o rádio num momento de transição nas indústrias midiáticas em que se consolidam novos intermediários, notadamente serviços de streaming, em que a curadoria humana foi progressivamente dando lugar a sofisticados sistemas de automação, reorganizando a escuta de música em larga escala.

1 Versão revista e ampliada de trabalho apresentado no encontro anual do Grupo de Pesquisa Rádio e Mídia Sonora, durante o $42^{\circ}$ Congresso Brasileiro de Ciências da Comunicação, realizado na Universidade Federal do Pará, em Belém (PA), em setembro de 2019. Agradecemos ao bolsista de pesquisa Rodrigo Caê, graduando em Produção Cultural pelo Instituto Federal do Rio de Janeiro (IFRJ), pelas contribuições à presente reflexão.

2 Universidade Federal do Rio de Janeiro (UFRJ). Rio de Janeiro, RJ, Brasil. https://orcid.org/0000-0002-4838-2162. E-mail: marcelokisch@gmail.com

3 Universidade Estadual de Maringá (UEM). Maringá, PR, Brasil. https://orcid.org/0000-0001-6997-4127. E-mail: guzferreira@gmail.com

4 Universidade Federal do Rio de Janeiro (UFRJ). Rio de Janeiro, RJ, Brasil. https://orcid.org/0000-0003-3763-4608. E-mail: musicabrpt@gmail.com

5 Universidade Federal do Rio de Janeiro (UFRJ). Rio de Janeiro, RJ, Brasil. https://orcid.org/0000-0002-6600-2610. E-mail: arturseidel@gmail.com

6 Universidade Federal do Rio de Janeiro (UFRJ). Rio de Janeiro, RJ, Brasil. https://orcid.org/0000-0003-2565-5073. E-mail: liana@forum.ufrj.br 
Palavras-chave: Rádio; programação musical; curadoria; automação; mediação algorítmica.

Abstract: This article investigates the process of building a radio programming, increasingly tensioned between two poles: human curation and the algorithmic mediation of automation software. We propose a discussion on the roles played by categories such as musical genres, diversity and repetition. The argument is based on the premise that music remains central to radio at a time of transition in media industries. This time of new intermediacy consolidation is marked by streaming services in which human curation has progressively given way to sophisticated automation systems, reorganizing music listening on a large scale.

Keywords: Radio; music programming; curation; automation; algorithmic mediation. 


\section{Introdução}

Encadear uma sequência de músicas de modo a engajar uma audiência, construindo ou capitalizando vínculos afetivos, é uma atividade que foi gradualmente alçada ao status de arte ao longo das últimas seis décadas. Com a consolidação das indústrias fonográfica e radiofônica, nos anos 1950, o disc-jockey (DJ) tornou-se um ícone pop, conhecedor de "boa música", articulador de festas e outros eventos sociais, um entertainer, mestre de cerimônias, em suma, um mediador cultural, apto a prescrever a públicos específicos o que se deveria ouvir, uma trilha sonora não só para as pistas de dança, mas para o cotidiano.

Esses atributos ganharam importância primeiramente com a expansão da Frequência Modulada, nos anos 1980, com a popularização da música eletrônica, nos 1990, e com os novos atores digitais da mídia sonora, nos 2000. Não é coincidência que os primeiros DJs, na virada dos anos 1950 para 1960, tenham se tornado celebridades, apresentando shows radiofônicos que levavam seus nomes e assinando coletâneas lançadas pela indústria fonográfica com sucessos do momento. O mesmo ocorreu com os DJs dos diversos subgêneros eletrônicos, muitos dos quais se tornariam astros internacionais. Talvez por isso, o pioneiro serviço de streaming, Last.fm, lançado em 2003, na Inglaterra, com a pretensão de ser a última FM - no sentido de que, depois dele, supostamente as emissoras musicais em ondas hertzianas perderiam sua razão de existir -, apresentasse, em sua página na internet, fotos e pequenos textos sobre seus mais de 40 programadores.

Esses perfis funcionavam como uma espécie de certificado da curadoria humana para um complexo sistema ancorado no software Audioscrobbler, que informava ao serviço cada música ouvida pelo usuário em seu computador e traçava, por meio de algoritmos, um perfil, formando sequências de músicas em fluxo contínuo. Em dez anos, o serviço acumulou mais de 43 bilhões de scrobbles, o que equivalia a uma playlist que levaria 391 mil anos para ser executada (KISCHINHEVSKY, 2016, p. 76). A categorização dos conteúdos em gêneros e subgêneros musicais, por meio de ferramentas de etiquetagem, rastreamento e distinção, 
desempenhava papel-chave no processo de identificação entre os ouvintes da Last.fm (AMARAL, 2007, p. 235-239) ${ }^{7}$, que funcionava como um híbrido de mídia social e plataforma de consumo musical.

Softwares de automação vêm gradualmente assumindo protagonismo, não apenas entre os novos atores do mercado digital de mídia sonora, mas também no rádio. A maioria absoluta das emissoras musicais incorporou às suas rotinas produtivas programas proprietários como Pulsar, Playlist e AVA ou gratuitos como Zara e Radio DJ, passando a encadear sua programação musical através de algoritmos. O papel do DJ programador, antes uma estrela radiofônica, está cada vez mais restrito à seleção de fonogramas que entrarão numa pasta de arquivos a partir da qual o software construirá sequências, muitas vezes a partir de parâmetros opacos ou simplesmente aleatórios. Quando muito, o programador interfere na frequência de execução de uma determinada faixa, a partir de ajustes no seu percentual de rotatividade, e determina - a partir de critérios subjetivos e/ou comerciais - quando o seu ciclo na programação deve se encerrar.

Entende-se, contudo, que há um fator de distinção que reverte em ganhos de audiência para emissoras que não abrem mão da seleção da programação musical por meio da curadoria humana. Rádios universitárias e educativas são exemplos da persistência de programadores de carne e osso, que até recorrem a softwares de automação, mas permanecem no comando do processo, acionando critérios artísticos para seleção e gestão de repertório - uma espécie de ativismo musical, que apela a valores como autenticidade, qualidade e exclusividade, em contraponto ao mainstream das paradas de sucessos homogeneizantes.

Neste artigo, discute-se essa tensão entre a mediação algorítmica e a curadoria humana no rádio, meio que, a despeito do avanço das plataformas digitais, permanece como espaço central na prescrição musical. Nada menos que $83 \%$ da população escutam emissoras radiofônicas

7 Comprada pelo CBS Interactive Music Group, em 30 de maio de 2007, a Last.fm perdeu audiência gradativamente, sobretudo quando começou a cobrar mensalidades. Ainda assim, em 2011 informava contar com cerca de 40 milhões de usuários ativos - o número deixou de ser atualizado após essa data. 
diariamente nas 13 maiores regiões metropolitanas do país, segundo dados da Kantar IBOPE Media ${ }^{8}$. A audiência é ainda maior (86\%) entre os mais jovens, e a programação musical desempenha papel-chave, sendo consumida por $93 \%$ dos ouvintes.

No percurso, revisamos a escassa literatura disponível sobre programação musical radiofônica, majoritariamente internacional e/ou dedicada a estudos de caso de emissoras comerciais (cf. ROTHENBUHLER, 1985; ROTHENBUHLER; MCCOURT, 1987; AHLKVIST; FISHER, 2000; AHLKVIST, 2001; AHLKVIST; FAULKNER, 2002; KISCHINHEVSKY; HENRIQUES, 2015; GAMBARO; VICENTE; RAMOS, 2018). Também se contextualiza o papel da música no rádio num momento de transição nas indústrias midiáticas em que se consolidam novos intermediários, notadamente os serviços de streaming (a respeito, cf. KISCHINHEVSKY; VICENTE; DE MARCHI, 2015; DE MARCHI, 2016; VICENTE; DE MARCHI; GAMBARO, 2016; KISCHINHEVSKY; DE MARCHI, 2016; VICENTE; KISCHINHEVSKY; DE MARCHI, 2018), a importância da curadoria humana (GAMBARO, 2016) e o crescimento da oferta de playlists, formato que tem assumido centralidade nas indústrias de mídia sonora (FERREIRA, 2017).

A presente reflexão é um desdobramento de cartografia da radiodifusão universitária desenvolvida ao longo dos últimos três anos (para resultados preliminares desta pesquisa, cf. KISCHINHEVSKY; MUSTAFÁ; PIERANTI; HANG, 2018; e KISCHINHEVSKY; MUSTAFÁ; MATOS; HANG, 2018), bem como da construção da programação musical da emissora da UFRJ, da qual quatro autores participaram diretamente ao longo de 2019.

A cartografia, com 106 emissoras identificadas até o momento (68 FMs, 33 web rádios e cinco AM), envolveu a aplicação de um questionário on-line com 57 respostas válidas e escuta sistemática de 24 horas de programação de 15 delas, selecionadas a partir de sua importância

8 Inside Radio 2019. Disponível em: https:/www.kantaribopemedia.com/download-inside-radio/. Último acesso: 4 nov. 2019. 
histórica, de sua relevância nos seus mercados de atuação e da representatividade regional e da vinculação (instituições de ensino superior públicas, privadas e confessionais, federais, estaduais e municipais, comunitárias). Os dados obtidos expõem o papel da música no rádio universitário: apenas uma emissora, entre todas as investigadas, trabalha exclusivamente com conteúdo jornalístico; todas as demais recorrem à programação musical para construir suas identidades e estabelecer vínculos com seus públicos-alvo.

Iniciamos a discussão, no entanto, com uma abordagem teórica sobre a relação entre gêneros musicais e a radiofonia, pensando ainda sobre as dinâmicas de repetição e inovação em torno das quais a indústria se estruturou nestas últimas décadas, com flagrantes desafios à diversidade da oferta de bens simbólicos.

\section{Formato canção e gêneros musicais como (problemáticas) unidades de análise}

Ao extrair o conteúdo de um compact disc (CD) para alimentar o acervo musical de uma emissora de rádio, é importante verificar se os fonogramas estão acompanhados dos metadados correspondentes, como título das faixas, autores, intérpretes, gravadora, ano de gravação, editora. Uma dessas informações, contudo, é usualmente descartada pelos programadores musicais, pois não reflete o que vai ser ouvido: na esmagadora maioria dos CDs gravados por artistas brasileiros nos principais selos fonográficos multinacionais, a música recebe o selo "Latina".

Não está em questão aqui a identidade latino-americana dos músicos brasileiros, mas sim o caráter homogeneizante da atuação das grandes gravadoras de discos, que nivelam toda a produção local a um rótulo que evoca uma latinidade imaginária, talvez existente apenas nos escritórios de marketing dessas empresas.

Esta é apenas a ponta de um enorme iceberg. Gêneros musicais foram construídos e tensionados ao longo do século XX como uma estratégia mercadológica. No Brasil e em outros países, por força da legislação, os 
discos em vinil, popularizados após a Segunda Guerra Mundial, traziam compulsoriamente indicações sobre como a música podia ser enquadrada numa perspectiva musicológica - marcha, marcha-rancho, maxixe, tango, bolero etc. Nas últimas décadas, no entanto, hibridizações dificultaram a demarcação de gêneros estabelecidos muitas vezes há mais de um século. As misturas de elementos diversos estão por trás, por exemplo, do surgimento do rock'n'roll, do hip hop, da música eletrônica e de outras manifestações artísticas que alargam fronteiras de gêneros e ressignificam rótulos estabelecidos.

Gêneros musicais desenvolvem-se entre os polos da consolidação e da abertura, ora lapidando, ora implodindo gramáticas específicas, em que a repetição de estruturas melódicas desempenha papel central (cf., por exemplo, FRITH, 1996; JANOTTI JR., 2006; e CARDOSO FILHO, 2008). Gêneros vendidos pela indústria fonográfica, no entanto, não coincidem necessariamente com segmentos explorados pela indústria radiofônica, abrindo um rico campo de disputas de sentido em que discursos imbuídos de juízos de valor e operações de distinção social incidem fortemente, auxiliando na identificação ou no rechaço de músicas, artistas e gêneros específicos por parte das audiências.

O rádio musical trabalha, majoritariamente, com o formato canção, consagrado pela indústria fonográfica no início do século XX. Apoiado na perspectiva da semiótica greimasiana do pesquisador e compositor Luiz Tatit, ex-integrante do grupo paulistano Rumo, Jorge Cardoso Filho (2008, p. 5) destaca que a canção se estrutura de uma maneira específica, num esquema que pode ser resumido com os seguintes elementos se sucedendo nesta ordem: estrofe $=>$ ponte $=>$ refrão $=>$ estrofe $=>$ refrão $=>$ solo $=>$ refrão.

De acordo com o pesquisador, a canção "possui um eixo LETRA $\times$ MELODIA estabilizado e apelo fundamental à voz de quem canta" (CARDOSO FILHO, 2008, p. 7). A gramática da canção se completa com a duração média em torno de 3 a 4 minutos, como resultado dos condicionamentos técnicos resultantes do suporte físico - os acetatos de 78 rotações por minuto, do início do século passado, só comportavam 
gravações desta extensão, o que exigiu a simplificação da estrutura da música produzida à época, em que predominavam a ópera, a música de concerto e manifestações (mais ou menos) populares de formatos variáveis, como samba de roda, polcas, valsas, maxixes.

O formato canção, portanto, transita por gramáticas de produção e reconhecimento que envolvem dois movimentos:

a) articulação entre LETRA - MELODIA vai ser promovida mediante o emprego de estratégias reconhecidas pelas dinâmicas expressivas da música. Isso implica que uma atenção fundamental deve ser dada à voz que canta aquela canção, pois a hierarquização nos usos de cada uma das dicções recai sobre o sentido final da manifestação expressiva, b) as estruturas de repetição melódicas, embora expressivamente diferentes, geralmente promovem uma desaceleração da canção, o que implica que suas funções são extremamente semelhantes (por isso chamamos de "estruturas de repetição") (CARDOSO FILHO, 2008, p. 8).

Alvo de estudos críticos, a repetição se torna chave para o reconhecimento (outra categoria amaldiçoada e associada à suposta regressão da escuta) e a apropriação da música pelo público em geral. Esse processo se aprofunda à medida que as indústrias fonográfica e radiofônica, constituídas a partir dos anos 1920, desenvolvem-se de modo profundamente imbricado. Ambas ganham força no Pós-Guerra, na virada entre os anos 1940 e 1950, quando se consolidam os discos de vinil - em 33 e 1/3 rotações por minuto, o chamado long-play (LP), e em $45 \mathrm{rpm}$, mais usado para singles - e os sistemas de gravação em fita magnética. O resultado desses avanços técnicos é a abundante oferta de fonogramas pré-gravados, em discos de tiragens cada vez maiores. No rádio, a ocupação da Frequência Modulada transformaria a forma como a música era ouvida: a prevalência das apresentações ao vivo na fase do rádio espetáculo daria lugar à música reproduzida em vinil.

O rádio, locus de veiculação da música registrada pela indústria fonográfica, já havia ajudado, desde as primeiras décadas do século XX, a consolidar o formato canção, operando numa dinâmica em que se estabeleciam hábitos de consumo musical, caracterizados em grande medida 
pela repetição de estruturas melódicas. Mas nem tudo é repetição: o rádio se notabilizaria também como espaço de prescrição de lançamentos musicais, em geral novidades que a indústria fonográfica busca enquadrar (associando-os a gêneros preestabelecidos) e comercializar.

Jeder Janotti Junior destaca que, diante do "excesso informacional" nas últimas décadas, que pressupõe forte segmentação, os campos da produção, da circulação e do consumo "se valem de rótulos extremamente codificados". Por isso, os gêneros seriam um elemento-chave "para a compreensão da produção de sentido das canções populares massivas".

Os gêneros seriam, então, modos de mediação entre as estratégias produtivas e o sistema de recepção, entre os modelos e os usos que os receptores fazem destes através das estratégias de leitura dos produtos midiáticos. Antes de ser um elemento imanente aos aspectos estritos da música, o gênero estaria presente no texto através de suas condições de produção e consumo. [...] O gênero musical é definido então por elementos textuais, sociológicos e ideológicos, é uma espiral que vai dos aspectos ligados ao campo da produção às estratégias de leitura inscritas nos produtos midiáticos (JANOTTI JR., 2006, p. 137-138).

O gênero deve, portanto, ser entendido como um modo de endereçamento da música, que passa a ser inserida em uma "gramática" específica. O pesquisador britânico Simon Frith (1996) sustenta que os gêneros musicais estruturam o mercado, estabelecendo parâmetros para a produção, a execução (performance ao vivo) e a escuta. Um artista assina contrato com uma gravadora na expectativa de que seu trabalho será produzido e endereçado a determinado público-alvo imaginado dentro de regras específicas, que condicionam desde a linguagem de um vídeo e de fotos promocionais até a dinâmica em estúdio.

As regras dos gêneros musicais são sempre relativas à sociedade e ao período histórico em que são formuladas. Operam sempre entre dois polos: a inovação - necessária à indústria, mas, eventualmente, desorientadora - e a consolidação - que proporciona alguma estabilidade e previsibilidade -, associadas à repetição. Gêneros surgem num 
movimento de organização do mercado da música, mas dependem de acordos tácitos entre os mais diversos atores - na época em que Frith escrevia, gravadoras de discos, emissoras de rádio, revistas musicais, promotores de shows, varejistas.

Os gêneros musicais que a indústria fonográfica tenta vender são, constantemente, objetos de disputa. Nesse sentido, Frith chama a atenção para a importância também das rádios, que passam a se segmentar nos mais diversos formatos a partir dos anos 1960 e vão testar os limites dos rótulos que as gravadoras buscam emplacar para vender mais. Só que essa segmentação atende a uma lógica muito distinta daquela das gravadoras - nos EUA, referência para o mercado brasileiro, formatos radiofônicos como "country”, "música clássica”, "jazz" e "pop contemporary hit radio" convivem com outros mais difíceis de definir, como "adult contemporary", "urban contemporary", "AOR (Album Oriented Rock)", entre outros.

A indústria radiofônica segmenta-se fortemente a partir dos anos 1960 e 1970, para capitalizar a diversificação social e cultural, muitas vezes em frontal desacordo com estratégias comerciais das grandes gravadoras. Emissoras musicais do segmento pop contemporâneo tendem a abrir espaços na programação para diversos gêneros de sucesso no momento, passando por cima de comunidades de gosto. Emissoras de outros segmentos, como adulto contemporâneo, rock, jazz, clássico etc., por sua vez, operam com regras mais estritas de gêneros, trabalhando para oferecer programações mais homogêneas, atendendo a parâmetros de identificação e distinção.

Para Frith, o gênero musical como estratégia de endereçamento de bens simbólicos pressupõe um consumidor idealizado.

[...] ao usar rótulos de gênero para tornar o processo de marketing mais eficiente, companhias de discos partem do princípio de que há uma relação administrável entre rótulo musical e gosto do consumidor. Isso reside, em contrapartida, numa série de suposições sobre quem são estes consumidores em termos de idade, sexo, etnicidade, disponibilidade de renda, hábitos de lazer, e por aí em diante. Em termos de uma pesquisa mais ampla de mercado, suposições como esta são em geral suficientemente 
eficientes [...]. Contudo, o que está havendo aqui é uma idealização, a criação de um consumidor de fantasia [...] e, nisso, a indústria segue o gosto mais do que a forma. [...] Ao decidir rotular uma música ou um músico de um modo particular, gravadoras de discos estão dizendo algo sobre o que as pessoas gostam e por quê; o selo musical age como um argumento sociológico e ideológico condensado. (FRITH, 1996, p. 85-86, tradução nossa)

Gêneros musicais estão o tempo todo sendo criados, testados, consolidando-se e tensionando seus próprios limites. Nesse sentido, acrescenta Frith, recoloca-se a questão das relações estabelecidas entre os prazeres da novidade e da repetição: gêneros populares estabelecem expectativas, e o desapontamento ocorre tanto quando elas não são atendidas quanto naqueles casos em que isso ocorre de modo muito previsível.

Essa lógica de consumo musical, atualmente, não se circunscreve às emissoras de rádio - entendidas como instituições mediadoras e balizadoras do gosto popular -, mas estende-se aos novos intermediários da mídia sonora. No streaming, a situação se complexifica, com gêneros musicais dividindo as atenções com moods (humores, estados de ânimo) como parâmetro de categorização dos fonogramas - estratégia que já reverbera na programação de algumas emissoras musicais. Pesquisa sobre o consumo de música realizada pela Box 1824, consultoria de tendências em consumo, comportamento e inovação, focou nas novas formas de mapeamento musical, considerando as semelhanças nas mensagens e especulando sobre o momento ideal para a audição de cada estilo. $\mathrm{O}$ estudo identificou que fatores subjetivos como estado de espírito, humor e disposição de ânimo são elementos considerados na hora da escuta.

Os moods categorizados pela pesquisa são: a) Dystopia (música pop reinventada - exemplos de artistas: Björk, Adele, Lorde); b) Heavy baile (música de rua, do gueto e de festas, como hip hop, música eletrônica e variações como trap e funk - ex.: M.I.A, Kanye West, Calvin Harris); c) Malícia melódica (músicas que falam de amor, sexo, paixão, sofrimento e desilusão - ex.: Thiaguinho, Luan Santana, MC Gui, Beyoncé etc.); 
d) Mass indie (artistas independentes que têm inserção no mercado, como Kings of Leon, Beirut e, no Brasil, Silva e Lucas Santtana) $)^{9}$.

Mas se observarmos a reestruturação dos serviços de streaming nos últimos dois anos, perceberemos que a especialização se tornou muito mais profunda, com a classificação de fonogramas em categorias ou playlists intituladas como Relaxante, Para Cantar Junto, Malhação, Alegre, Festa, Romance, Zen, Foco, Orgulho LGBTQi etc.

\section{Playlist no rádio e no streaming: aproximações e diferenças}

O endereçamento realizado pelos gêneros musicais (ou pelos moods) ocorre na programação musical, por meio do estabelecimento do formato segmentado. A ferramenta decisiva para uma programação musical segmentada do rádio, posteriormente adotada também pelas plataformas de streaming, é o desenvolvimento de regras e procedimentos para a definição de um formato específico de comunicação. Este formato é a playlist, que identifica o veículo com um segmento de atuação, ao estabelecer compromissos de oferta de música aos públicos desejados.

A playlist é o produto final de um processo de seleção baseado em discussões culturais e técnicas e disputas econômicas que pressupõem um ouvinte imaginado, com o qual aquela lista específica guarda maior ou menor aderência. Sua construção depende principalmente desta característica profissionalizante: a intencionalidade comunicativa em arregimentar certo público para certa sequência de canções. Constitui a unidade básica de uma programação musical radiofônica.

No rádio e no streaming essa construção discursiva por meio da playlist é fundamental, mas seus processos são diferentes no sentido em que enfatizam elementos e fontes de informação diferenciados. No rádio, segundo Ahlkvist (2001, p. 345-347), há uma disputa entre quatro eixos

9 Cf. "Pesquisa propõe nova forma de categorizar os estilos musicais por humores". UAI, 2015. Disponível em: https:/www.uai.com.br/app/noticia/musica/2015/08/27/noticias-musica, 171060/pesquisa-propoe-nova-forma-de-categorizar-os-estilos-musicais-por-humores.shtml. Última visita: 28 jun. 2019. 
"filosóficos" fundamentais que orientam uma curadoria feita pelo programador: foco na indústria ou na audiência e julgamentos estéticos ou "racionais". No streaming, em que predomina a automação, este embate não é central porque a digitalização e o uso de algoritmos pressupõem a racionalização. Entretanto, ao contrário das comunidades de gosto, da identificação da estação e da conexão de quem prescreve a música com o ouvinte, prioriza-se a necessidade de personalização aos gostos, momentos e atividades do ouvinte, uma playlist especial para cada um e para cada momento. Em ambas as mídias, porém, o impulsionador da eleição de critérios e concepções de ouvinte é a necessidade de identificar um público e torná-lo subscritor desta dada prescrição, em razão da veiculação de anúncios ou pagamento de assinaturas.

A playlist aparece no rádio, ainda de acordo com Ahlkvist, como uma gramática de temporalidade, uma metanarrativa resultante da programação musical. A preocupação central nos estudos de rádio, entretanto, é a tendência de padronização que envolve a aplicação das mesmas playlists através do rádio. A programação pela playlist se produz como uma demarcadora temporária das comunidades de gosto, construindo repertórios e reforçando práticas de seleção específicas. Para Berland (1990, p. 182), uma construção que tende à padronização orientada por processos técnicos e administrativos dos grandes centros econômicos, principalmente quando se considera a tendência de concentração de controle sobre o rádio a partir da desregulamentação ocorrida nos EUA durante os anos 1990. Um exemplo, podemos acrescentar, é o formato pop contemporary hit radio, um dos mais populares nos EUA e no Brasil, que opera na lógica do top 40 - ou seja, uma lista fechada de 40 fonogramas que são martelados ao longo da programação da emissora a cada 2 ou 3 horas, a partir de relações comerciais com selos fonográficos e pressupostos do que o deve ou não ser um hit, um sucesso de audiência.

Todavia, uma crítica dessa perspectiva "apocalíptica" da padronização procura oferecer uma análise mais profunda das interações entre imposições comerciais e visões do próprio papel do programador. É o que apresentam Rothenbuhler (1985) e Ahlkvist, Faulkner e Fisher 
(2002; 2000), ao observarem que essas estratégias podem ser entendidas como ligadas às identidades do programador: (1) como representante de uma marca e responsável por sua identidade; (2) como "curador" de conteúdos adequados aos ouvintes; e (3) como promotor de músicas com potencial para ser sucesso comercial.

Rothenbuhler e McCourt (1987, p. 108) descrevem como os processos de seleção no rádio comercial são percebidos prioritariamente como rotinas profissionais, com categorias predefinidas de formato, aceitação e potencial. Iniciam-se com a "sensibilização", em que se avaliam o universo de fonogramas disponíveis e quais são prioridades para a estação e, na sequência, pensam-se o espaço disponível na programação e os fonogramas selecionados em relação aos já estabelecidos no repertório. Esse processo rotineiro, nos anos 1980, levava menos em conta pedidos de ouvintes, vendagens de discos e outras rádios do que informações de promotores da indústria fonográfica, recomendações de especialistas, reputação de artistas, espaço na programação e percepções subjetivas dos diretores musicais sobre o potencial de alcançar um hit. Há grande preocupação em estabelecer uma reputação ou credibilidade ao trabalho desenvolvido e nos resultados obtidos por essa seleção.

A característica principal desse olhar profissional sobre a construção da programação consiste na base comercial que o regula. Em outras palavras, este procedimento é predominantemente regulado pela lógica de gestão de negócios e não, necessariamente, pela lógica comunicativa ou educativa. Em grande parte, assim, o público é avaliado em termos de segmentos de audiência, ou como consumidor, tipificado de acordo com lógicas de mercado e não como interlocutor em um processo de trocas simbólicas. A reputação é construída em termos de diferentes segmentos priorizando não o ouvinte, mas os outros profissionais ( $\mathrm{RO}$ THENBUHLER, 1985, p. 212).

Já Ahlkvist e Faulkner (2002, p. 196) propõem um detalhamento das variações de práticas dos responsáveis que parta para um estudo da produção da cultura, ou seja, situe na subjetividade dos programadores e sua negociação com a racionalização profissional uma análise mais 
compreensiva e qualitativa. É assim que apresentam a ideia de filosofias de programação, que descreve abordagens de programadores para legitimar a construção da playlist. As filosofias representam os valores hierarquizados que determinam a seleção musical, compartilhados discursivamente no mundo profissional do rádio. Assim, programadores lidam com oposições binárias: estética ou pesquisa, sobre seleção das músicas, e atender aos ouvintes ou à empresa/indústria, sobre seu papel. A determinação de posições em alguns desses eixos orientará, para Ahlkvist (2001, p. 345), as práticas de seleção.

Nesse contexto, a estética ocupará lugar central nos fatores de qualidade musical e da subjetividade do "ouvido" do programador. O gosto e o conhecimento do programador são chaves nessa filosofia. A outra posição concentra-se na racionalização da seleção. Busca-se a objetividade e utilização de dados, ignorando-se a audição da música em si. Nesse caso há uma valorização profissional e procedimental da seleção, com base em dados de audiência e pesquisas com ouvintes.

No eixo do papel exercido pelo programador, em um extremo uma filosofia situa o programador como um consumidor substituto, ou seja, como alguém que seleciona as músicas imaginando-se o ouvinte da rádio e daqueles fonogramas, orientando-o, mas com foco na experiência do ouvinte. Nesse caso, porém, o conhecimento musical ou a subjetividade são vistos como possível empecilho ao programador, pois é preciso compreender a perspectiva do ouvinte, não a do profissional. $\mathrm{O}$ alcance dos objetivos de mercado da emissora e da indústria fonográfica é o foco central. Nesta última, a interpretação das pesquisas e do conteúdo artístico é papel da gravadora, que subsidia o programador, intermediário entre as estratégias da indústria e o público.

Tais estudos exibem como a lógica do rádio comercial organiza a programação musical. Entretanto, nas emissoras sem fins lucrativos essas filosofias são significativamente diferentes. Tim Wall (2007, p. 36) observa que a construção da programação de rádios universitárias norte-americanas é, em um grau mais acentuado, associada a uma atuação política e à promoção de música alternativa ou independente. 
Wall demonstra que um discurso de "alternatividade" nessas rádios é baseado em uma variedade de repertórios diferentes que operam em conjunto com as histórias culturais que envolvem tais repertórios e não é limitado a um discurso de gênero musical específico. A construção de uma "alternatividade" orienta escolhas das canções e sua apresentação em acordo com uma predominância de discursos progressistas, educativos e de contracultura predominantes nas mídias sem fins lucrativos dos EUA. Assim, a definição de alternativo mostra-se variável de acordo com relações culturais e políticas.

Essa perspectiva se assemelha às filosofias "não-racionais" de Ahlkvist (2001, p 345), em que a preocupação é orientada à educação, à empatia com o ouvinte e com os valores estéticos das músicas selecionadas, mas acrescenta dimensão política à análise. Além disso, a ideia de autenticidade, associada à produção discursiva do gênero musical discutida por Frith, reaparece aqui associada aos discursos "alternativos".

Toda essa lógica aplicada à curadoria humana da programação musical pode servir de quadro teórico para os serviços de streaming, principalmente pela percepção de que o "toque humano" é essencial para a identificação destes serviços como canais de música e não apenas bibliotecas de dados (GLANTZ, 2016, p. 45-46). Entretanto, diante da dimensão dos dados disponíveis para a organização da programação e da ênfase do mercado digital na personalização do acesso aos conteúdos, o uso de algoritmos para filtragem, seleção e ofertas aos usuários sempre foi peça-chave. Essa necessidade também se justifica pela tentativa de enquadramento de tais empresas não como empresas de mídia musical, mas como empresas de tecnologia - ainda que seus discursos se sustentassem pesadamente na remediação do rádio como o fluxo contínuo, a identificação com o serviço e a especialidade das ofertas musicais (ERIKSSON et al., 2019, p. 12).

Usando a perspectiva das filosofias de programação para análise, na automação predominará a racionalidade, principalmente pela necessidade de quantificar e transpor para chaves numéricas comportamentos subjetivos como a definição de gêneros e seus discursos, altamente 
usadas por curadores, sobre sensações, sentimentos e atividades ligadas à audição de determinadas músicas, como estados emocionais e atividades físicas.

Ainda está por se demonstrar, porém, se a construção de tais algoritmos imbuídos também de uma intencionalidade comunicativa preenche os mesmos papéis que a programação da playlist radiofônica.

\section{Considerações finais}

O rádio musical enfrenta um desafio inédito ao encarar uma concorrência que não mede sua audiência em milhares de ouvintes por minuto, mas sim em centenas de milhões de assinantes, como é o caso de Spotify, Deezer, Apple Music e outros serviços de streaming - que também podemos chamar de rádio social -, todos com acervos superiores a 50 milhões de fonogramas. A automação de processos, como a gestão de catálogos e a rotatividade de faixas na programação, é incontornável, diante do enfraquecimento do mercado radiofônico, com queda de faturamento e inédita perda de postos de trabalho. Muitos programadores musicais hoje respondem pela curadoria de duas, três ou mais emissoras, simultaneamente, equilibrando-se entre interesses comerciais e critérios artísticos.

Entendemos que, ao abrirem mão da curadoria humana em suas programações, muitas emissoras assinam os próprios atestados de óbito, com sua oferta de bens simbólicos tornando-se indistinta daquela trazida pelos novos atores do entorno digital. A segmentação, nesse sentido, pode ser uma armadilha, fazendo com que o ouvinte permaneça em terreno conhecido e não se surpreenda com qualquer faixa inserida na playlist. Entendemos que gêneros musicais, tratados de forma estanque, engessam a construção de uma programação musical e podem criar falsos dilemas. "Rock" pode ser entendido como um rótulo voltado para um público jovem, embora o gênero exista há mais de 60 anos. "Samba", por sua vez, apresenta mil subdivisões - "pagode”, "samba de raiz", "partido alto", por exemplo - que operam muito mais no campo discursivo do que no musicológico, dificultando, e muito, a mediação algorítmica. 
O caráter homogeneizante da segmentação do rádio comercial no Brasil e a subordinação das dinâmicas de circulação musical às estratégias de vendas das companhias fonográficas aumentam a responsabilidade dos programadores radiofônicos no sentido de não reiterar esses processos, que prejudicam a diversidade na oferta de bens simbólicos e a veiculação de manifestações artísticas preteridas pela mídia de referência. Infelizmente, essa preocupação se manifesta em poucas emissoras, geralmente universitárias e/ou públicas de caráter educativo, que em geral não perseguem audiências massivas.

Fica patente, contudo, a necessidade de que as emissoras de rádio (re)estabeleçam canais de realimentação da programação musical, que deve ser constantemente renovada, com uma escuta efetiva das demandas da audiência, sem desconsiderarmos também a estrutura de divulgação das gravadoras de discos ${ }^{10}$.

Escutamos uma programação musical porque reconhecemos grande parte daquelas músicas (constituem uma gramática familiar para nós, que integramos determinadas comunidades de gosto), mas não apenas por isso. Queremos também ser surpreendidos, tendo acesso a lançamentos ou relembrando sucessos do passado, que evocam memórias, reminiscências de outros tempos que recordamos com carinho. Inovação e repetição caminham de mãos dadas, configurando hábitos de escuta mais ou menos voláteis, condicionados por diversos outros fatores, inclusive estéticos e políticos.

Advoga-se aqui que, apesar da inviabilidade de se elaborar manualmente uma programação musical que se estenda 24 horas por dia, de segunda a segunda, o programador radiofônico de carne e osso faz diferença para o futuro do meio. E, nesse sentido, este profissional precisa recuperar seu status de artista, de conhecedor de música e das complexas tramas de sentido que a permeiam, construindo laços, vínculos entre emissora e audiência. $\mathrm{O}$ trabalho do programador, sobretudo nas

10 Em visita do primeiro autor a uma das emissoras acompanhadas durante a cartografia da radiodifusão universitária, surpreendentemente foi constatado que há orçamento para aquisição mensal de CDs, que poderiam ser obtidos gratuitamente junto às gravadoras, como parte de sua estratégia de divulgação. 
emissoras sem fins lucrativos, precisa se pautar por filosofias de programação "não-racionais", como diria Ahlkvist, mas que conciliem parâmetros técnicos (diversidade de gêneros, pluralidade de artistas, representatividade das faixas selecionadas, equilíbrio entre lançamentos e sucessos do passado, que proporcionam um efeito de reconhecimento) e afetivos (acionamento de mecanismos de subjetivação, identidade, gosto).

O rádio musical sobreviveu às playlists individualizadas em MP3 ouvidas em dispositivos móveis, mas, diante do crescimento exponencial da oferta de fonogramas trazida pelos serviços de streaming, forçosamente tem que se diferenciar da racionalidade imposta pelos softwares de automação. E o único caminho para isso é a curadoria humana qualificada, levada a cabo com iguais doses de inteligência e envolvimento emocional.

Esperamos que essas reflexões contribuam para o debate sobre a construção de programações radiofônicas musicais, ampliando a discussão teórica sobre um tema ainda tão negligenciado nos estudos de rádio e mídia sonora.

\section{Referências}

AHLKVIST, J. A. Programming philosophies and the rationalization of music radio. Media, Culture ๒ Society, v. 23, n. 3, p. 339-358, 2001.

AHLKVIST, J. A.; FAULKNER, R. “Will This Record Work for Us?”: Managing Music Formats in Commercial Radio. Qualitative Sociology, v. 25, n. 2, p. 189-215, 2002.

AHLKVIST, J. A.; FISHER, G. And the hits just keep on coming: Music programming standardization in commercial radio. Poetics, v. 27, n. 5-6, p. 301-325, 2000.

AMARAL, A. Plataformas de música on-line: práticas de comunicação e consumo através dos perfis. Contracampo (UFF), n. 20, ago. 2009.

CARDOSO FILHO, Jorge. Emergência do sentido na canção midiática: uma proposta metodológica. Intexto. Porto Alegre: UFRGS, v. 1, n. 18, jan./jun. 2008.

BERLAND, J. Radio space and industrial time: Music formats, local narratives and technological mediation. Popular Music, v. 9, n. 2, p. 179-192, 1990.

DE MARCHI, L. A destruição criadora da indústria fonográfica brasileira, 1999-2009: dos discos físicos ao comércio digital de música. Rio de Janeiro: Folio Digital/Letra e Imagem, 2016.

ERIKSSON, M.; FLEISCHER, R. et al. Spotify Teardown: Inside the Black Box of Streaming Music. Cambridge: MIT Press, 2019. 
FERREIRA, G. Uma revisão bibliográfica do conceito de playlist. In: Anais do 40ํㅡongresso Brasileiro de Ciências da Comunicação, Curitiba, 2017.

FRITH, S. Performing rites: On the value of popular music. Cambridge: Harvard University Press, 1996.

GALLEGO PÉREZ, J. I. User-Generated Playlists: Radio Music Programming in the Age of Peer-to-Peer Production, Distribution and Consumption. In: BONINI, T.; MONCLÚS, B. (Org.). Radio Audiences and Participation in the Age of Network Society. NY: Routledge, 2015.

GAMBARO, D.; VICENTE, E.; RAMOS, T. S. A divulgação musical no rádio brasileiro: da "caitituagem" aos desafios da concorrência digital. Contracampo, v. 37, n. 2, ago./nov., 2018.

GAMBARO, D. Curadoria Smart: reflexão sobre o papel do rádio na relação com a indústria musical. In: Anais do 39o Congresso Brasileiro de Ciências da Comunicação, SP, 2016.

GLANTZ, M. Internet radio adopts a human touch: A study of 12 streaming music services. Journal of Radio \& Audio Media, v. 23, n. 1, p. 36-49, 2016.

HESBACHER, P. Sound exposure in radio: The misleading nature of the station playlist. Popular Music and Society, v. 6, n. 2, p. 105-117, 1978.

JANOTTI JUNIOR, J. Mídia e música popular massiva: dos gêneros musicais aos cenários urbanos inscritos nas canções. In: PRYSTHON, A. (Org.). Imagens da cidade: Espaços urbanos na comunicação e cultura contemporâneas. Porto Alegre: Sulina, 2006. KISCHINHEVSKY, M.; MUSTAFÁ, I.; PIERANTI, O. P.; HANG, L. Rádios universitárias no Brasil: Um campo em constituição. Revista Latinoamericana de Ciencias de la Comunicación, v. 15, n. 9, p. 132-142. Alaic: 2018.

KISCHINHEVSKY, M.; MUSTAFÁ, I.; MATOS, C. M.; HANG, L. Por uma historiografia do rádio universitário no Brasil. Revista Brasileira de História da Mídia (RBHM), v. 7, n. 2. São Paulo: Rede Alcar, 2018.

KISCHINHEVSKY, M.; DE MARCHI, L. Expanded radio. Rearrangements in Brazilian audio media markets. Radio, Sound \& Society Journal, v. 1, p. 75-89, 2016.

KISCHINHEVSKY, M.; HENRIQUES, P. R. Memória afetiva e (re)construção de marca de uma emissora musical pioneira em FM no Brasil. Inmediaciones de la Comunicación, v. 10, n. 10, p.131-144, 2015.

KISCHINHEVSKY, M.; VICENTE, E.; DE MARCHI, L. Em busca da música infinita: os serviços de streaming e os conflitos de interesse no mercado de conteúdos digitais. Fronteiras - Estudos Midiáticos, v. 17, n. 3, p. 302-311, 2015.

ROTHENBUHLER, E. W. Programming Decision Making in Popular Music Radio. Communication Research, v. 12, n. 2, p. 209-232, 1985.

ROTHENBUHLER, E. W.; MCCOURT, T. Commercial Radio and Popular Music: Processes of Selection and Factors of Influence. In: LULL, J. (Org.). Popular Music and Communication. Beverly Hills: Sage, 1987. p. 101-115. 
164 ENTRE O ALGORITMO E A CURADORIA

VICENTE, E.; KISCHINHEVSKY, M.; DE MARCHI, L. A consolidação dos serviços de streaming e os desafios à diversidade musical no Brasil. Eptic On-Line (UFS), v. 20, p. 25-42, 2018.

VICENTE, E.; DE MARCHI, L.; GAMBARO, D. O rádio musical no Brasil: elementos para um debate. In: ZUCULOTO, V.; LOPEZ, D.; KISCHINHEVSKY, M. (Org.). Estudos radiofônicos no Brasil - 25 anos do Grupo de Pesquisa Rádio e Mídia Sonora da Intercom. São Paulo: Intercom, 2016.

WALL, T. Finding an alternative: Music programming in us college radio. Radio Journal: International Studies in Broadcast \& Audio Media, v. 5, n. 1, p. 35-54, 2007.

\section{Sobre os autores}

Marcelo Kischinhevsky - Professor do Núcleo de Rádio e TV da Universidade Federal do Rio de Janeiro (UFRJ) e do Programa de Pós-Graduação em Comunicação da Universidade do Estado do Rio de Janeiro (UERJ). No presente artigo, o autor contribuiu com a estrutura e a redação final do artigo.

Gustavo Ferreira - Professor de Comunicação e Multimeios da Universidade Estadual de Maringá (UEM) e doutor em Comunicação pela Universidade do Estado do Rio de Janeiro (UERJ). No presente artigo, o autor contribuiu com as reflexões teóricas sobre as relações entre playlist e programação musical radiofônica, bem como sobre a tensão entre curadoria e mediação algorítmica.

Claudia Góes - Doutora em Ciências Musicais pelo Instituto de Etnomusicologia da Universidade Nova de Lisboa (INET/UNL), Portugal, mestre em Comunicação e Cultura pela UFRJ, jornalista e radialista. No presente artigo, a autora contribuiu com as reflexões teóricas sobre gêneros musicais e o papel dos moods (estados de ânimo) no rádio e no streaming.

Artur Seidel - Doutorando em Comunicação e Cultura pela UFRJ e mestre pela mesma instituição. Bolsista do Núcleo de Rádio e TV da UFRJ. No presente artigo, o autor contribuiu com a discussão sobre a construção de uma programação musical radiofônica, a partir da experiência da Rádio UFRJ.

Liana Monteiro - Mestranda em Comunicação e Cultura e graduada em Comunicação Social, habilitação Radialismo, pela Escola de Comunicação da 
UFRJ, servidora técnico-administrativa do Núcleo de Rádio e TV da mesma instituição. No presente artigo, a autora contribuiu com a discussão sobre a construção de uma programação musical radiofônica, a partir da experiência da Rádio UFRJ.

Data de submissão: 03/12/2019

Data de aceite: 07/08/2020 